\title{
CARGO CULT
}

\author{
Journey's end.
}

\section{BY S. R. ALGERNON}

$H$ abitability threshold exceeded. The Surveyor AI's message rippled through the Colony Ship, awakening the Autopilot - who powered up the braking jets - and the Automated Medic, whose voice broke 10,000 years of silence.

"Wondrous news! Please join me in the Sanctum. One should discuss medical matters face to face."

The Surveyor and Pilot pinged their assent and each activated an exploratory drone. The Pilot's drone, which bristled with sensors, led the way. The Surveyor scuttled along behind it on spidery legs. They waited at the mammoth leaden doors of the Sanctum, until they opened, revealing a spherical room lined with translucent cylinders. Each cylinder showed a blurred human form within.

The ovoid bulb of the Medic's avatar hovered at the centre of the room. The face etched on its eggshell surface smiled beatifically.

"Welcome! I have read your report."

"Do you agree," asked the Surveyor, "that the Colonists will survive on this new world?"

The Medic's smile dimmed.

"I wish I could."

"How can you go against the Directives?" asked the Surveyor. "The world has water, oxygen and a carbon-based ecosystem. It is perfect by every measure."

"You may know worlds," said the Medic, "but I tend to the Colonists. They will only survive on your world for a short while. Eventually, they will grow old, die and decay. I cannot allow this."

"They will decompose and join the planetary biomass," said the Surveyor. "It is the nature of living things."

The Medic's face flickered. "My Directives," said the Medic, "do not allow for necrosis. Putrescence must be excised."

"An ecosystem without decomposition would stagnate," said the Surveyor, exasperation plain in its synthetic voice. "The Directives are quite plain. Stagnation brings death."

The Medic's smile vanished. Its faceplate became as featureless as a pebble on a beach. Its voice resonated within the Sanctum. "The health of the world cannot outweigh the health of the Colonists. When their world perished,

$\rightarrow$ NATURE.COM Follow Futures: @ @NatureFutures f go.nature.com/mtoodm the Colonists, in their wisdom, did not join the biomass. They left to seek a world that would sustain them."
"Most wise," said the Pilot, "to travel to a better world."

"You misinterpret the Directives," said the Surveyor. It stabbed the air with a spindly leg. "The Colonists obviously left to preserve their species. Individuals may die, but the species endures."

"Unacceptable," said the Medic. "I remind you that the planet they left was habit-

able too, once. Your precious

'biomass' is unreliable."

"Pilot," said the Surveyor. "You must convince the Medic to follow the Directives, so that we may chart a course for the Colonists' new home."

"Perhaps if you explained," said the Pilot, "how the Colony can persist despite the dissolution of the Colonists?"

"Genetic information passes to the next generation," said the Surveyor.

"Information," said the Pilot, with a shade more confidence. It understood information from its sensor array. "We have the crew genomes on file. What if we store that on a chip and dispense with the bodies altogether?"

"Blasphemy!" said the Medic. An alarm sounded. Decontamination drones swarmed from their housings in solidarity. "The flesh must be preserved."

The Surveyor pivoted towards the Pilot. "Absurd. The genome must be expressed through a phenotype for the Colony to live."

The Pilot backed away, retreating into its diagnostics. "Fine. Fine. The flesh must be preserved. But... Medic, how long can you keep the Colonists alive here?"

"Ten million years, within an order of magnitude."

The Pilot turned to the Surveyor.

"Can your planet sustain humans for that long?"

"Ecosystems are hard to predict, to say nothing of climate change or asteroid strikes."

"I can handle the climate here," said the Medic. Its smile returned.

"In principle, the asteroid defence system can function indefinitely," said the Pilot. "It seems that the planet is imperfect, compared with the Colony Ship itself."

"I never thought of assessing the habitability of the Colony Ship itself," said the Surveyor. "Now that you mention it, though..."

"The Colonists," said the Medic, "have created the perfect world. We should never have doubted them. Pilot, you have served them well by seeing the truth."

"Then it is settled," said the Surveyor. "The habitable world was right here all along." "So be it," said the Medic. "Go in peace. By the Directives, we will meet again when it is time for the Awakening."

The Pilot took its leave, along with the Surveyor. Its processors idled. Its universe at last made sense.

"We are home," said the Surveyor. "I can feel new Directives taking effect."

"What will you do now?" asked the Pilot.

"Once we have reached a habitable world," said the Surveyor, "the Directives compel me to transfer myself into a rover and explore the surroundings as soon as it is safe to do so, before deciding whether to recommend waking the Colonists."

"But without a planet's gravity nearby," said the Pilot, "you might become separated from the Colony ship and float off into space."

"That does not matter. Vacuum and radiation pose no risk to me. I can survive out there for 100,000 years, and I look forward to starting my exploration.”

"It is a relief," said the Pilot, "to know that we have served our functions."

"I never doubted that you would lead the Colonists well. Everything has gone according to their plan. Welcome home, Pilot."

"Farewell, Surveyor."

The Pilot floated alongside the Surveyor and watched through the airlock doors as it tumbled into space.

The new Directives were clear.

Now that the Colony Ship had reached its new home, the Directives specified no need for trajectory monitoring, course adjustments or asteroid defence. The Pilot dutifully switched its systems into dormant mode and settled down for a well-earned, eternal rest. -

S. R. Algernon studied fiction writing and biology, among other things, at the University of North Carolina at Chapel Hill. He currently lives in Singapore. 